\title{
Proteção e promoção do investimento estrangeiro no Mercosul - uma ferramenta para a implementação de um bom clima de investimentos?
}

\author{
Protection and promotion of foreign investment in \\ MERCOSUR - a tool to the implementation of a good \\ investment climate?
}

JOSÉ AUGUSTO FONTOURA COSTA*

Rev. Bras. Polít. Int. 49 (2): 60-77 [2006]

\section{Introdução}

Um dos principais desafios do Direito Internacional na atualidade é a criação e sedimentação de sistemas normativos internacionais capazes de incrementar a segurança jurídica internacional, mediante a qual os fluxos econômicos internacionais seriam facilitados pela redução de riscos políticos e custos transacionais.

Um dos campos onde a capacidade de regulação internacional se apresenta com maior profundidade é o das relações econômicas, sobretudo no sentido da imposição de alguns limites importantes à ação dos Estados, o que ocorre tanto mediante as instituições de Bretton Woods - o Banco Mundial e o Fundo Monetário Internacional - quanto no sistema da Organização Mundial do Comércio (OMC). Em muitos casos é possível identificar claramente obrigações claramente imputadas aos Estados e que, pelo menos em alguns casos, estão sujeitas a decisões por terceiros, normalmente órgãos técnicos ou de solução de controvérsias.

Não obstante, embora o investimento estrangeiro, sobretudo na sua modalidade direta, tenha grande complexidade e permeie os sistemas regulatórios internacionais mencionados, não está submetido a um regime multilateral específico para sua promoção e proteção.

Em decorrência disso, os diversos atores relevantes para os investimentos, dos quais podemos facilmente destacar as companhias transnacionais (TNCs),

* Doutor em Direito Internacional (USP); Professor da Universidade Católica de Santos e Professor da Universidade do Estado do Amazonas; jafcosta@uol.com.br 
os Estados e a sociedade civil organizada, buscam seus objetivos em um ambiente onde a capacidade regulatória está classicamente concentrada nos Estados, que podem cooperar ou competir na busca de investimentos estrangeiros. Nesse sentido, as TNCs buscam marcos regulatórios mais favoráveis a suas atividades e à sociedade civil, mediante diversos objetivos instrumentais, busca melhorias de qualidade de vida e de participação nos processos decisórios.

No presente trabalho se analisa a ação dos Estados mediante a assinatura e a ratificação de acordos internacionais de investimento, buscando avaliar, a partir da estrutura desses acordos e dos padróes históricos de desenvolvimento de sua rede, se podem ser encontrados indícios de cooperação interestatal para a formação de bons climas de investimento.

Para tanto, analisaremos, especificamente, o caso da Argentina, com o objetivo de compreender como os tratados internacionais em matéria de investimento podem ser utilizados como instrumentos regionais e sub-regionais de cooperação.

\section{Contexto e ideologia do Mercosul}

Nas décadas de 1960 e 1970 as políticas de desenvolvimento de diversos países latino-americanos seguiram as receitas cepalinas, as quais se caracterizavam pela proteção temporária dos mercados internos contra a importação de bens estrangeiros, criando defesas para a indústria nascente, ao mesmo tempo em que os Estados se endividavam externamente, buscando recursos para investimentos em educação e infra-estrutura, principalmente nos setores de transporte, energia e comunicaçōes. Visava-se, destarte, trazer investimentos estrangeiros diretos para setores produtivos, os quais buscariam mercados internos, atraindo, consigo, capitais e tecnologia.

De fato, é possível considerar que os investimentos estrangeiros são, em grande medida, uma alternativa para a exportação de bens e serviços. Além de barreiras resultantes de custos de transporte e de adaptação dos produtos à regulamentação e às preferências dos consumidores estrangeiros, portanto, se buscava, mediante um muro de proteção tarifária, incentivar a instalação de empresas estrangeiras.

Do ponto de vista institucional, a tentativa frustrada de formar uma zona de livre comércio na América Latina por meio da Associação Latino-Americana de Livre Comércio (Alalc), que tinha como membros os países latinos da América do Sul e o México, não conseguiu diminuições significativas de tarifas de importação e, muito menos, um incremento significativo dos fluxos comerciais na regiáo. Iniciada pelo Tratado de Montevidéu de 1960, a Alalc foi dissolvida, vinte anos depois, com o Tratado de Montevidéu de 1980 que criou a Associação Latino-Americana de Integração (Aladi), ainda existente e em funcionamento. Embora a finalidade da Aladi seja mais ambiciosa - a 
formação de um mercado comum latino-americano - seus princípios e instrumentos imprimem bastante flexibilidade para o acordo, admitindo diversas exceções à cláusula de nação mais favorecida.

A crise do endividamento dos anos 80 , a qual afetou profundamente muitos países, bem como problemas inerentes ao próprio modelo e seu sistema de implementação, fizeram com que este fosse considerado como fracassado. De fato, o desequilíbrio departamental, conforme o qual o setor de produção de bens de capital e os investimentos em pesquisa e desenvolvimento não se transplantaram para os novos mercados, bem como a inexistência de mercados suficientemente amplos para fazer com que os benefícios de escala pudessem ser totalmente aproveitados terminou por implicar na ineficiência do setor produtivo, ao mesmo tempo em que, inclusive como decorrência das crises do petróleo dos anos 70, o endividamento estatal se tornou insustentável. Os chamados tigres asiáticos, por seu turno, obtiveram sucessos bastante significativos com estratégias voltadas à exportação, sem deixar de lado os investimentos e a interferência do Estado.

Do ponto de vista ideológico, as políticas radicalmente liberais adotadas por Margaret Thatcher, no Reino Unido, e Ronald Reagan, nos Estados Unidos a partir de 79 e 80 , respectivamente, passaram a ser tomadas como alternativas razoáveis ao estado de bem estar social e ao estado desenvolvimentista. Com a Queda do Muro de Berlim, em 89, e a dissolução da União Soviética, em 92, tendências neoliberais passaram à condição de discurso dominante, provocando importantes resultados não apenas nos países em transição do socialismo para o capitalismo, mas também para países em desenvolvimento da África e da América Latina.

É nesse contexto que é negociado e firmado o Tratado de Assunção.

Com efeito, em 1986, Argentina e Brasil elaboraram um acordo para a criação de livre comércio entre ambos os países. A fim de evitar um relativo isolamento na região, por iniciativa do Paraguai e do Uruguai, iniciaram-se as negociaçõos que levaram, cinco anos depois, à assinatura do Tratado de Assunção, que criou o Mercado Comum do Sul, ou Mercosul, inscrito na Aladi como um acordo de alcance parcial de complementação econômica (ACE 18, de 29 de novembro de 1991).

O Mercosul indica como sua finalidade a formação de um mercado comum - que supõe a livre circulação de mercadorias, capitais e pessoas, com liberdade de estabelecimento. No entanto, suas normas, anexos e protocolos se voltam à formação de uma união aduaneira - livre circulação de mercadorias e tarifa externa comum - que ainda não chegou a se aperfeiçoar.

De fato, a concepção do Mercosul já se apresenta em um contexto de implementação de planos de liberalização pelos governos dos quatro países, envolvendo, em graus variáveis, desregulamentação, ajustes financeiros ortodoxos, privatizações e liberalização comercial. $\mathrm{Na}$ implementação dessas 
políticas, os discursos voltados às opiniōes públicas nacionais constantemente apontavam para as necessidades derivadas da globalização e, em muitos casos, apontavam o próprio Mercosul como um instrumento de desenvolvimento, o qual poderia ser prejudicado mediante a manutenção de políticas de desenvolvimento adotadas em períodos anteriores.

É subjacente à formulação da estrutura jurídica e institucional do Mercosul que a abertura de mercados é uma ferramenta que favorece o crescimento e o bem estar. Embora se mencione explicitamente a necessidade de coordenação de políticas macroeconômicas, não há qualquer gérmen de políticas econômicas comuns, as quais constituem um dos pilares de sustentação da União Européia desde o Tratado de Roma de 1957.

Embora não se possa negar que o Mercosul produziu efeitos positivos a respeito do comércio intra-regional, também é importante ressaltar que a consolidação de um sistema de união aduaneira parece já haver se mostrado como o limite histórico deste sistema.

De qualquer modo, o Mercosul foi um fator de aumento significativo do acréscimo das correntes comerciais entre os membros. Pode-se supor que, pelo menos parcialmente, isso foi resultado de criação de comércio, ao passo que, sem dúvida, outra parte foi resultado de desvio de comércio. O desvio de comércio, em geral considerado como um efeito negativo da integração regional, tem entre seus efeitos evitar que a competição com produtos de outras regióes, com sistemas de produção mais eficientes, seja evitada ou, pelo menos, retardada. Isso pode não ser tão mau em um contexto no qual indústrias antiquadas podem depender de tempo e investimentos para se adaptarem à abertura comercial. Os chamados efeitos dinâmicos da integração viriam, em algum tempo, a anular os aspectos negativos do desvio de comércio, proporcionando um ambiente de concorrência e complementação entre as economias capazes de reduzir custos de produção e incentivar inovações. A integração, pelo menos, proporcionou a reestruturação de empresas, expandindo mercados de modo a possibilitar o aproveitamento de economias de escala.

Assim, o contexto em que se formou o Mercosul era fortemente marcado por tendências de liberalização, impulsionadas tanto pela estagnação resultante da crise do endividamento dos anos 80 , quanto pela dissolução política do bloco soviético. Políticas de desregulamentação, austeridade financeira, privatização e liberalização comercial estavam na ordem do dia. Nesse ambiente o Mercosul têm duas importantes funçôes: a) auxiliar o desenvolvimento dos discursos internos de liberalização, os quais apontavam para a integração regional, pautada por moldes livre-cambistas - como um instrumento necessário para a inserção internacional e b) oferecer uma alternativa intermediária para aberturas unilaterais ao comércio internacional, buscando possibilitar que parte do comércio desviado pudesse servir como proteção para as indústrias locais, as quais, em muitos setores, não poderiam sobreviver a uma abertura unilateral. 


\section{Atração de investimentos estrangeiros}

Por que investir em um país estrangeiro? Há, sem dúvida, uma série importante de dificuldades que tendem, em muitos casos, a desencorajar os investidores, as quais vão da instabilidade macroeconômica às diferenças culturais, passando pelo sistema jurídico e jurisdicional. Em muitos setores de bens e serviços a exportação destes pode ser uma alternativa bastante viável e, portanto, é necessário explicar por que essas dificuldades são enfrentadas e investimentos diretos são feitos na implementação e na modernização de filiais estrangeiras ao invés de nas matrizes.

Existe um corpo de teoria microeconômica bastante variado a respeito da atração dos investimentos estrangeiros, sendo que Elias Gannagé (1985, p. 25 a 119) indica cinco principais grupos de teorias explicativas: a) comportamento oligopolístico; b) aversão ao risco; c) teoria da informação; d) teorias ecléticas de base cíclica; e e) teorias ecléticas contemporâneas.

Buscando sumarizar as principais causas de atração, Dunning (1993) identifica quatro tipos de motivos de investimentos estrangeiros diretos, os quais podem ser sintetizados na tabela a seguir:

Tabela 1

\begin{tabular}{ll}
\hline Busca de recursos & - recursos naturais (minérios, matérias primas ou áreas \\
& para agricultura ou pecuária); \\
& mão-de-obra barata ou especializada. \\
\hline Busca de mercados & mercados anteriormente servidos por importações ou \\
& com altas barreiras à importação; \\
& fornecedores que acompanham seus clientes em \\
& expansão para o exterior. \\
\hline Busca de eficiência & $\begin{array}{l}\text { integração e racionalização vertical ou horizontal das } \\
\text { cadeias produtivas. }\end{array}$ \\
\hline Busca de ativos estratégicos & $\begin{array}{l}\text { - aquisições, fusões e alianças com objetivos estratégicos } \\
\text { de longo prazo. }\end{array}$ \\
\hline
\end{tabular}

Embora a identificação analítica dos motivos para o investimento estrangeiro seja importante para a compreensão das políticas de atração de investimentos, é necessário ter em conta que os investidores observam todos esses aspectos e atuam com base em mesclas de incentivos e barreiras. Deste modo, por exemplo, um país que tem mão-de-obra muito barata pode ser preterido em favor de um onde, até como decorrência do preço mais elevado das horas de trabalho, há mercados mais atraentes. Os fatores considerados, portanto, podem ser de diversas ordens e, decerto, variam conforme o setor da economia. 
Assim, o cálculo passa pela busca de vantagens, as quais vão além da simples alternativa da exportação. $\mathrm{O}$ aumento da venda de bens intermediários para as filiais e a melhor presença comercial podem, destarte, compensar amplamente a estratégia baseada na simples exportação de bens e serviços ${ }^{1}$. Os locais são escolhidos, portanto, em virtude da presença de diversos elementos, incluída a estrutura jurídica².

Por conseguinte, as políticas de atração de investimentos estrangeiros buscam contemplar, mesmo que em diferente intensidade, os diversos elementos que possam influenciar positivamente as decisóes dos investidores estrangeiros. Dentre os instrumentos que podem ser utilizados para a criação de um ambiente favorável ao investimento estão a criação de estabilidade macroeconômica e o estabelecimento de um marco regulatório adequado.

Considerando que os recursos disponíveis internacionalmente são relativamente escassos, é fundamental compreender quais as estratégias estatais possíveis para o incremento dos fluxos positivos de capitais, a respeito das quais a internacionalização de estruturas regulatórias pode ser uma alternativa de grande significância.

\section{Juridificação internacional e estabilização do ambiente regulatório}

No contexto deste trabalho, juridificação significa a utilização de instrumentos de Direito Internacional, tanto de ordem normativa quanto jurisdicional, para promover a estabilização de expectativas referentes ao comportamento de Estados e outros atores relevantes para as relaçóes internacionais. Trata-se de um esforço de ocupação de espaços de ação política, tendentes a limitar os custos de oportunismo, particularmente os referentes à ruptura dos acordos estabelecidos.

No que se refere a seu âmbito de operação e aos atores envolvidos, Lars Blichner e Anders Molander afirmam que ${ }^{3}$ :

A juridificação, do modo que a compreendemos, ocorre em um ordenamento jurídico ou na constituição de um ordenamento jurídico, seja no patamar nacional, internacional ou supranacional. Esta é um processo no sentido de que aumenta com o tempo. Se o processo for revertido, falaremos em desjuridificação. Os 'atores'

\footnotetext{
${ }^{1}$ BRENTON, Paul, MAURO, Francesca di and LÜCKE, Matthias. "Economic Integration and FDI: an empirical analysis of foreign investment in the EU and in Central and Eastern Europe", in Empirica, $\mathrm{n}$. 26, 1999, p. 104-109.

2 PICCIOTTO, Sol. "Linkages in international investment regulation: the antinomies of the draft multilateral agreement on investment", in University of Pennsylvania Journal of International Economic Law, n. 19, 1998, p. 744-745.

3 BLICHNER, Lars Chr. e MOLANDER, Anders. "What is juridification?", in Arena Working Paper, n. 14. Oslo: Arena Center for European Studies, 2005, p. 5, T. do A.
} 
envolvidos, de modo amplo, são os governos, legislaturas, atores administrativos, Judiciário, juristas e outros atores não-estatais, incluídos os indivíduos e as empresas.

Decerto, trata-se de um fenômeno complexo e que, do ponto de vista normativo, tem defensores e críticos em um debate no qual, por um lado, apontase a estabilização de expectativas e, por outro, a redução de âmbitos de debate e participação política ${ }^{4}$. No campo do Direito Internacional, particularmente, é constante a crítica de que, em situações extremas, os Estados podem, sempre, deixar de observar as normas jurídicas.

No âmbito deste artigo, no entanto, será dada atenção ao caráter funcional da juridificação como redutora de incertezas políticas, inclusive na medida em que é capaz de incorporar novos atores além dos tradicionais sujeitos de Direito Internacional, nomeadamente Estados e Organizações Internacionais. Esse enfoque tem a finalidade de servir como instrumento de análise para os processos de juridificação no âmbito do Mercosul, particularmente em relação ao investimento estrangeiro.

É possível identificar dimensões da juridificaçãos:

- a da obrigatoriedade, que se refere ao compromisso dos Estados e outros atores de atuarem conforme regras;

- a da precisão, que se refere à definição clara e não ambígua das condutas; e

- a da delegação, mediante a qual se garante autoridade a terceiros para implementar e interpretar as regras e, em alguns casos, até mesmo resolver controvérsias e criar novas normas.

A partir da juridificação é possível, portanto, encontrar diferentes mesclas e intensidades de vinculação e ancoragem dos direitos internos e a limitação do campo de ação dos Estados. Deste modo, é possível ajustar a intensidade de controle de instâncias estatais de tomada de decisão e, por conseguinte, limitar os riscos de comportamento oportunista, ao mesmo tempo em que se reduz a instabilidade potencial ${ }^{6}$ (ABOTT e SNIDAL, 2000, p. 430).

Como um dos fatores levados em conta no processo decisório para a alocação de investimentos estrangeiros é a estrutura jurídica e institucional, a utilização da juridificação internacional pode ter duas funções fundamentais para a oferta de ambientes favoráveis:

\footnotetext{
${ }^{4}$ Idem, p. 5-7.

5 ABBOTT, Kenneth W. KEOHANE, Robert O., MORAVCSIK, Andrew, SLAUGHTER, Anne Marie, e SNIDAL, Duncan. "The Concept of Legalization". In: International Organization, vol. 54, n. 3. Cambridge, Ma: IO Foundation and the MIT, 2000, p. 401.

6 ABBOTT, Kenneth W. e SNIDAL, Duncan. "Hard and Soft Law in International Governance". In: International Organization, vol 54, n. 3. Cambridge, Ma: IO Foundation and the MIT, 2000, p. 430.
} 
- Reforma e modernização do quadro legislativo e institucional; e

- Estabilização dos riscos políticos mediante a internacionalização de regras e instâncias de solução de controvérsias.

A modernização do quadro legislativo e institucional tem sido, em regra, deixada aos ordenamentos internos. Com efeito, as transformaçôes dos marcos regulatórios tem sido realizadas com base nas políticas legislativas internas e sem a utilização de instrumentos internacionais de harmonização.

Por outro lado, a internacionalização tem servido, historicamente, como uma ferramenta para a proteção de investimentos estrangeiros. O primeiro campo em que houve importantes desenvolvimentos foi o da solução de controvérsias, às vezes baseada em contratos internacionais, às vezes em leis internas. Já nos anos 50 houve importantes arbitragens internacionais envolvendo investidores privados e Estados, o que se institucionalizou a partir do sistema do Centro Internacional para a Solução de Disputas sobre Investimentos (Cisdi), instituído pela Convenção de Washington de 65, sob os auspícios do Banco Mundial.

Multilateralismo, regionalismo e bilateralismo - identificando o locus da promoção e proteção de investimentos estrangeiros

A juridificação internacional de questôes econômicas vem sendo realizada em três patamares distintos, nos quais se apresentam padrôes diversos de cooperação.

Em primeiro lugar, apoiado, sobretudo, na OMC, ressaltada a importante participação de diversos organismos especializados das Naçôes Unidas, está um âmbito multilateral. A OMC chama de multilaterais os acordos válidos para todos seus membros, reservando a denominação "plurilateral" para os acordos que não abrangem todos os membros. No âmbito desse artigo, chamaremos de multilaterais os acordos cuja abrangência é tendente à universalidade, havendo adesão de países representantes das diversas regiōes do mundo e envolvendo os principais atores em um campo de ação. Essa definição de trabalho, bastante flexível, é suficiente para o presente ensaio, até porque este não se volta ao estudo detalhado ou aprofundado desses acordos, mas dos regionais e bilaterais.

No que se refere especificamente ao tema dos investimentos, a exceção das limitações a requisitos de desempenho postas pelo Trip's, o fracasso do Multilateral Agreement on Investments da OCDE e a obstrução ao tema na agenda da OMC praticamente afastam a liberalização e a regulamentação dos investimentos do marco multilateral.

Ainda no âmbito multilateral, por outro lado, é importante considerar o sistema das instituições de Bretton Woods, o Banco Mundial e o FMI. O principal sistema de solução de controvérsias, consubstanciado do Centro Internacional para Solução de Disputas sobre Investimentos (Cisdi), é resultante 
dos esforços do Banco Mundial, que levaram à celebração da Convenção de Washington de 1965. Do mesmo modo, a Agência Multilateral de Garantia de Investimentos (Miga), criada em 1986, também partiu dos esforços dessa Organização Internacional. Tanto o Cisdi quanto a Miga tem autonomia jurídica em relação ao Banco, sendo criados por convenções autônomas, as quais têm distintos signatários e aderentes. O FMI, por seu turno, tem impactos importantes no que se refere aos investimentos estrangeiros, sobretudo mediante a regulamentação da liberalização de fluxos de capitais e das garantias de pagamento das operações de conta corrente.

No âmbito da Aladi não existem acordos em matéria de investimento, sendo que as principais regras e princípios dessa Associação se voltam a questões comerciais. No âmbito específico do Mercosul há dois protocolos em matéria de promoção e proteção de investimentos estrangeiros, nenhum destes em vigor. O Protocolo de Colônia para a Promoção e Proteção Recíproca de Investimentos, de 1994, tem por objeto a promoção e proteção de investimentos intra-regionais. O Protocolo de Buenos Aires sobre a Promoção e Proteção de Investimentos Provenientes de Estados Não-Partes do Mercosul, também de 1994, o qual tampouco entrou em vigor, dispóe sobre investimentos extrazona, buscando oferecer alguns padrōes de proteção, sem, no entanto, muita profundidade.

Efetivamente, os principais instrumentos jurídicos internacionais de promoção e proteção de investimentos estrangeiros terminam por ser os acordos de promoção e proteção recíproca de investimentos (Appri's), especialmente na forma de tratados bilaterais sobre investimentos (TBIs). O número de TBIs firmados e ratificados em 2004 chega a pouco mais de $1.700^{7}$.

De fato, embora existentes desde 1959, os TBIs tiveram seu momento de maior expansão na década dos 1990. acompanhando a onda liberal, a qual atingiu até mesmo os países latino-americanos, tradicionalmente pouco afeitos a estes tratados. No mesmo período houve grande adesão à Convenção de Washington de 65 pelos países da América do Sul.

Dentre os países do Mercosul o Brasil é a única exceção no que se refere à ratificação desses acordos. Embora este país tenha firmado 14 acordos nos anos 90, não chegou a ratificar nenhum destes. A Argentina tem 58 acordos firmados, dos quais 53 estão em vigor. Tanto o Paraguai, quanto o Uruguai têm, cada um, mais de vinte TBIs em vigor ${ }^{8}$.

Deste modo, pode-se afirmar que o tratamento multilateral dos investimentos estrangeiros é bastante limitado, abrangendo um importante sistema de solução de controvérsias (Cisdi), uma agência de seguros contra

\footnotetext{
7 Unctad/WEB/ITE/IIA/2005/10.

8 Dados sobre TBIs: http://www.unctad.org/Templates/Page.asp?intItemID=2344\&lang=1, Disponibilidade 13 de junho de 2006. Dados referentes a $1^{\circ}$ de junho de 2006.
} 
riscos políticos (Miga) e algumas regras sobre circulação de capitais nos Artigos do FMI. No âmbito regional, embora em outras regiōes integradas, como Nafta, Cafta e EU sejam comuns sistemas de liberalização e proteção de investimentos, o Mercosul teve pouco ímpeto para liberalizar e proteger investimentos, tanto no que se refere aos originários da própria região (Protocolo de Colônia de 1994), quanto na oferta unilateral de proteção (Protocolo de Buenos Aires de 1994).

No entanto, a maior parte dos países da região estão bastante comprometidos com a sistemática das redes de Appri's, os quais são os principais instrumentos de regulação e proteção internacional de investimentos estrangeiros. Deste modo, a avaliação da cooperação regional potencialmente instrumentalizada por esses acordos necessita ser estudada, tendo em vista tanto a estrutura normativa destes, quanto os padrôes de disseminação global e regional.

\section{Estrutura dos Appri's - assimetrias?}

Os Appri's variam bastante conforme os seus signatários e a época em que foram firmados. Buscando uma configuração bastante ampla do conteúdo desses acordos, podemos identificar as seguintes cláusulas:

- Finalidade de promover e proteger os investimentos estrangeiros;

- Âmbito material: definições de investimento estrangeiro;

- Âmbito pessoal: definiçōes de investidor estrangeiro;

- Definição da cobertura pós ou pré entrada, com listas setoriais;

- Cláusula de nação mais favorecida;

- Cláusula de tratamento nacional;

- Tratamento justo e eqüitativo e proteção integral;

- Regras contra a expropriação, estabelecendo padrões de indenização;

- Regras de proteção integral, inclusive contra guerras civis e desordem interna;

- Regras sobre a transferência de capitais;

- Regras sobre sub-rogação em matéria de seguros;

- Regras sobre pessoal técnico e administrativo estrangeiro;

- Regras que proíbem o estabelecimento de requisitos de desempenho;

- Regras sobre transparência;

- Exceções gerais;

- Regras sobre o direito aplicável à solução de controvérsias;

- Regras sobre a solução de controvérsias entre investidores e Estado;

- Regras sobre a solução de controvérsias entre Estados;

- Regras estabelecendo padróes ambientais mínimos e

- Regras estabelecendo padróes laborais mínimos.

Considerando as dimensões de juridificação indicadas, é possível afirmar que os Appri's tem uma estrutura bastante forte. A análise das determinaçóes destes acordos deixa bastante claras as obrigações dos Estados na oferta de 
proteção aos investimentos e investidores estrangeiros, as quais são garantidas por sistemas internacionais de solução de controvérsias, que afastam os casos das cortes nacionais e, embora deixem espaço a negociações diplomáticas e comerciais, criam uma alternativa clara à negociação, inclusive, para os membros do Cisdi, com sistemas eficientes de execução e, portanto, de aplicação de sanções. Com efeito, o sistema dos Appri's pode ser identificado como um dos mais fortes instrumentos de juridificação internacional.

No entanto, as obrigações e regras claras e fortes estão concentradas no campo da proteção dos investimentos estrangeiros. As regras sobre liberalização são, em geral, pouco operativas e dependem da negociação de listas de setores. As normas sobre padrões ambientais e trabalhistas costumam ser, por seu turno, bastante flexíveis, apresentando às vezes pouca precisão e clareza, ao mesmo tempo em que quase nunca permitem a conformação de obrigaçōes concretas. No mesmo sentido, é bastante comum que a solução de controvérsias esteja limitada às regras de proteção de investimentos e investidores, excluindo-se, em geral, a liberalização e o estabelecimento padrões mínimos trabalhistas e ambientais.

Os Appri's são, de fato, acordos de proteção do investimento estrangeiro. A promoção depende da eficiência da proteção, tida como necessária para o estabelecimento de um bom clima de investimentos ${ }^{9}$. Estes acordos reduzem riscos transacionais, especialmente os regulatórios e políticos, o que pode incrementar a credibilidade dos países receptores.

Deste modo, sendo que a promoção dos investimentos é, em geral, deixada a cargo dos efeitos colaterais positivos da proteção e, em alguns casos, da liberalização, há uma importante crítica a respeito do funcionamento desses acordos, a qual denuncia seu caráter assimétrico, favorecendo, antes de mais nada, os investidores de países industrializados, em detrimento da possibilidade de regulamentação soberana dos investimentos ${ }^{10}$.

A própria negociação dos Appri's já indicariam a assimetria, como afrima Muthucumaraswamy Sornarajah ${ }^{11}$ :

A assimetria é inerente à formação destes tratados. Às vezes tratados bilaterais sobre investimentos são sustentados pela manutenção de promessas ou ameaças de sanções. Outras vezes, o tratado é feito como condição para um empréstimo. Nesse último caso, o problema da iniqüidade é acentuado.

\footnotetext{
${ }^{9}$ LOEWNEFELD, Andreas F. "Investment agreements and international law". Columbia Journal of Transnational Law, n. 42, 2003, p. 126-127. SALACUSE, Jeswald W. e SULLIVAN, Nicholas P. "Do BITs really work? An evaluation of bilateral investment treaties and their grand bargain". Harvard International Law Journal, n. 46, 2005, p. 74-78.

10 SORNARAJAH, M. The International Law of Foreign Investment, $2^{\mathrm{a}}$ Edição. Cambridge: Cambridge University Press, 2004, p. 207-208.

11 Op. cit., p. 218, T. do A.
} 
É uma hipótese que faz sentido. A análise das regras dos tratados vigentes leva, efetivamente, à clara percepção de que a força da juridificação referente à proteção de investimentos e investidores é bastante mitigada no que se refere à própria liberalização e, principalmente, no estabelecimento de padrões trabalhistas e ambientais, para os quais falta a criação de obrigações claras e, muitas vezes, a cobertura do sistema de solução de controvérsias. Por outro lado, fatos como a modificação do TBI modelo americano devido aos riscos detectados pelos Estados Unidos a partir da análise da arbitragem a respeito do artigo 1.105 do $\mathrm{Nafta}^{12}$ e o fracasso das negociaçóes do Acordo Multilateral sobre Investimentos (MAI), devido, entre outros fatores mais imediatos ${ }^{13}$, ao temor de perda de soberania ${ }^{14}$, parecem oferecer sustentação à hipótese da assimetria e da imposição.

Por fim, um outro argumento possível decorre da análise dos padrões de formação de redes de TBIs. A Alemanha, por exemplo, assinou mais de 140 TBIs, dos quais apenas um envolve outro membro da OCDE. No entanto, a afirmação de que os países da OCDE já estão, por seus sistemas jurídicos internos, imunizados contra riscos regulatórios e políticos, deve ser levada em conta. Tanto a criação de confiança, quanto o estabelecimento de padrões mínimos seria desnecessária entre estes países.

Não obstante, a análise do padrão dos acordos entre países em desenvolvimento pode ser mais significativa, pois se poderia produzir sinergias resultantes de estratégias de harmonização jurídica e de padrōes econômicos.

Há um sensível crescimento do número e da proporção geral dos TBIs entre países em desenvolvimento. Ao final de 99, 40\% dos TBIs eram entre países desenvolvidos e em desenvolvimento, uma proporção bastante diversa dos da década anterior, em que esta atingia os $68 \%{ }^{15}$. Os TBIs entre países em desenvolvimento passaram de 44 no ano de 90 para 653 em julho de 2004, alcançando $28 \%$ do total desses acordos ${ }^{16}$.

Destarte, embora da análise jurídica referente às obrigaçôes, clareza de regras e sistema de solução de controvérsias aponte firmemente para a assimetria entre direitos dos Estados e direitos dos investidores estrangeiros, é aceitável a hipótese de que estes acordos possam servir de instrumento de cooperação entre países em desenvolvimento, especialmente na medida em que fortalecem a credibilidade e harmonizam padrões mínimos.

\footnotetext{
12 GANZ, David A. (2004) "The evolution of FTA Investment Provisions: from NFTA to the United States - Chile Free Trade Agreement". In: American University International Law Review, n. 19, 2004. 13 PICCIOTTO, Sol. (1998) "Linkages in international investment regulation: the antinomies of the draft multilateral agreement on investment". In: University of Pennsylvania Journal of International Economic Law, n. 19.

14 STERN, Brigitte. (2000) "How to regulate globalization". In: The Role of Law in International Politics (BYERS, M. Organizador). Oxford: Oxford University Press.

15 Unctad/ITE/IIA/2, 2000, p. 4.

16 Unctad/WEB/ITE/ITT/2006/1, 2006.
} 


\section{Estudo do caso argentino e a mudança do padrão de assinaturas}

Tomando o caso da Argentina para a análise desses acordos no âmbito latino-americano encontramos ${ }^{17} 58$ acordos firmados, dos quais 53 estão em vigor. O primeiro destes acordos, firmado com a Itália, data de 22 de maio de 1990 e o mais recente, firmado com o Panamá, de 15 de setembro de 2004. Dos 24 países da OCDE, 19 têm TBIs em vigor com a Argentina. Os outros 38 acordos são com países em desenvolvimento, 14 dos quais da América Latina e Caribe.

Levando em conta as classes de países e as datas de assinatura dos acordos, encontramos a seguinte distribuição:

Distribuição de acordos

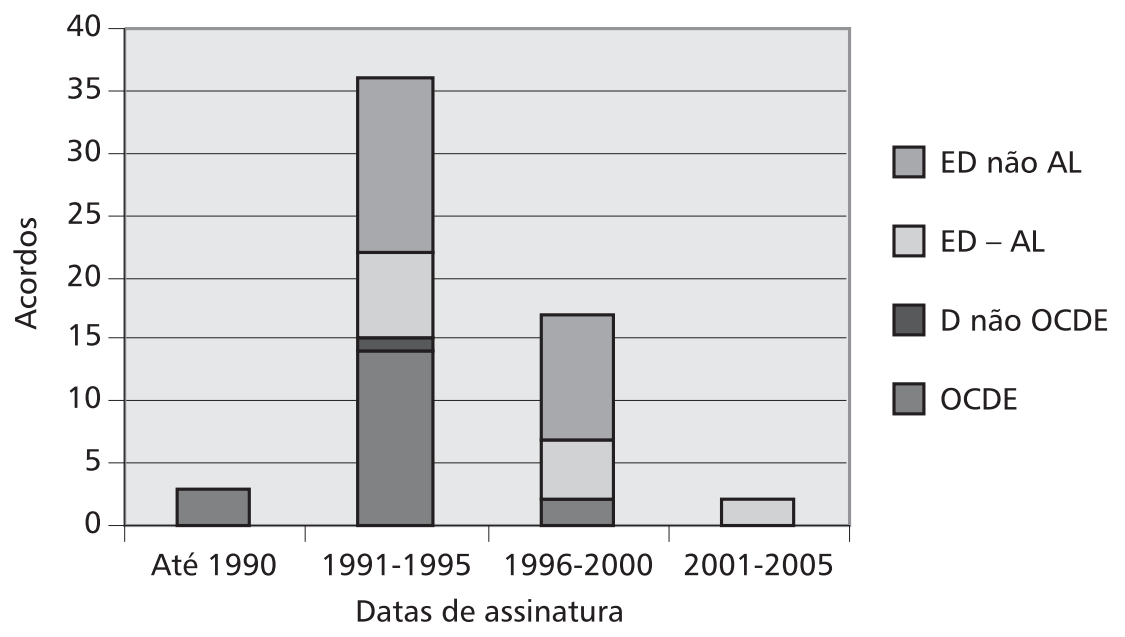

Embora os TBIs existam desde o final dos anos 50, estes acordos eram raros na América Latina, onde passaram a ser firmados a partir dos anos 80 e, principalmente, na década de 90 . De fato, o padrão geográfico das redes de TBIs parte, nos anos 60, de acordos entre países industrializados da Europa e países africanos ou socialistas europeus, seguindo, nos anos 70, para a Ásia e, a partir do final dos anos 80 , vencendo a resistência dos países latinoamericanos ${ }^{18}$.

17 Dados sobre TBIs: http://www.unctad.org/Templates/Page.asp?intItemID=2344\&lang=1. Disponibilidade: 13 de junho de 2006. Dados referentes a $1^{\circ}$ de junho de 2006. Classificação de países em desenvolvidos e em desenvolvimento conforme o Banco Mundial: http://web.worldbank.org/WBSITE/ EXTERNAL/DATASTATISTICS/0, contentMDK:20421402 - menuPK:64133156 - pagePK: 64133150 - piPK:64133175 -theSitePK:239419,00.html. Disponibilidade: 13 de junho de 2006.

18 Salacuse e Sullivan, 2005, p. 72 a 74; Tobin e Ackerman, 2005, p. 6; Unctad/ITE/IIA/2, 2000, p. 14 a 16. 
Nesse sentido, os acordos argentinos seguem os casos típicos, o que também ocorre a respeito da adesão ao Cisdi, assinada a Convenção de Washington de 1965 em 1991 e ratificada em 1994.

Ainda no tocante aos TBIs argentinos, é interessante notar uma modificação no padrão de distribuição da participação dos países em desenvolvimento. Como se pode verificar nas figuras abaixo ${ }^{19}$, os acordos com estes países deixaram de representar pouco mais de $50 \%{ }^{20}$ do universo dos acordos para chegarem a quase um terço ${ }^{21}$ dos acordos argentinos.

Distribuição em 2000

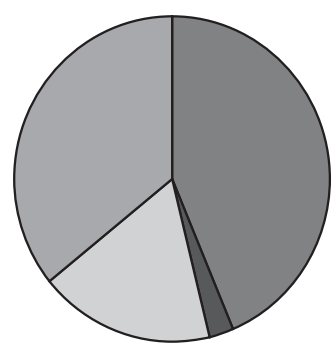

OCDE
Distribuição em 2005

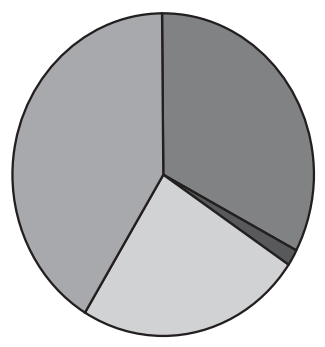

ED - AL $\square$ ED não AL

Houve, ademais, a firma dos dois protocolos mercosulinos já mencionados, o que terminou por barrar a assinatura de TBIs na região.

\section{Análise do caso argentino: indícios de cooperação?}

A experiência da Argentina é bastante peculiar em relação aos Appri's. Esse país não apenas firmou e ratificou um grande número desses acordos, como, depois da crise cambial de 2000 e 2001, terminou por ser réu em mais de trinta casos entre investidor e Estado só no Cisdi.

Do ponto de vista das políticas econômicas internas, é difícil negar uma importante frustração com o desenho das ações neoliberais adotadas durante o governo Menem e tratadas com pouca habilidade durante o governo radical de De la Rúa.

\footnotetext{
19 Dados sobre TBIs: http://www.unctad.org/Templates/Page.asp?intItemID=2344\&lang=1. Disponibilidade: 13 de junho de 2006. Dados referentes a $1^{\circ}$ de junho de 2006. Classificação de países em desenvolvidos e em desenvolvimento conforme o Banco Mundial: http://web.worldbank.org/WBSITE/ EXTERNAL/DATASTATISTICS/0, , contentMDK:20421402 - menuPK:64133156 -pagePK: 64133150 piPK:64133175 - theSitePK:239419,00.html. Disponibilidade: 13 de junho de 2006.

$2053,8 \%$ dos acordos.

${ }^{21} 65,5 \%$ dos acordos.
} 
O trauma argentino é particularmente significativo no que se refere aos Appri's e ao sistema de solução de controvérsias, sendo as arbitragens do Cisdi constantemente criticadas na imprensa nacional como resultantes de concessōes abusivas.

A despeito disso, a Argentina firmou acordos posteriormente ao default, seguindo uma tendência já clara de ampliar o âmbito desses acordos para países em desenvolvimento e, em particular, da América Latina.

Uma motivação pode ser a crença de que a juridicização incrementa a credibilidade e a confiança internacionais, favorecendo a constituição de um bom clima de investimentos. Nesse sentido, acordos com países para os quais o fluxo de entrada ou saída de capitais não chega a ser de grande significação para nenhum dos dois membros podem ser interpretados como desenhados para enviar a mensagem de participação em um consenso amplo a respeito da promoção e proteção de investimentos estrangeiros. Assim, a posição dos países em desenvolvimento membros de uma rede de Appri's regionais poderia ser apresentada como consensual em torno da noção de proteção dos ativos estrangeiros, o qual não seria apenas o resultado episódico de barganhas ou imposições de países exportadores de capital. Destarte, a ampliação de uma rede de Appri's poderia ter efeitos positivos para a melhora do clima de investimento, independentemente do crescimento de fluxo de capitais imediatamente associado com os acordos entre países em desenvolvimento.

A Argentina parece optar pela busca de redes regionais de Appri's, embora a inexistência de acordos desse tipo entre os membros do Mercosul seja significativa. A falta de profundidade do processo de integração sub-regional, no entanto, parece explicar, pelo menos parcialmente, essa lacuna de regulação internacional. Ainda assim, considerando os outros 11 membros da Aladi, a Argentina tem TBIs com sete (Bolívia, Chile, Cuba, Equador, México, Peru e Venezuela). Se dos quatro restantes forem excluídos os três outros sócios do Mercosul, restaria apenas a Colômbia sem acordo. Além disso, Paraguai e Uruguai também participam de redes de Appri's, as quais incluem, para cada um, cinco outros sócios na Aladi.

Por outro lado, esses acordos não parecem ser um instrumento para a liberalização regional dos fluxos de capitais e de serviços, uma vez que a estrutura mais clássica de proteção forte e de fragilidade de padrōes de estabelecimento de obrigações claras e de utilização de sistemas de solução de controvérsias para aspectos referentes à liberalização e à fixação de padróes trabalhistas e ambientais é a adotada nesses acordos ${ }^{22}$. Destarte, o impulso ao aumento de fluxo de capitais continua sendo, nesses acordos, um efeito colateral da redução de riscos e custos transacionais.

\footnotetext{
22 Unctad/WEB/ITE/ITT/2006/1, 2006.
} 
Assim, no caso dos acordos argentinos, a cooperação parece estar limitada à formação de um consenso regional, o qual, no entanto, se vê comprometido por diversos limites, notadamente:

- a ausência do Mercosul da rede de tratados argentinos;

- o caráter relativamente fraco desses acordos, que ressaltam o tema da proteção dos investimentos estrangeiros, sem regulamentar com maior profundidade temas como a liberalização e a adoção de padrões mínimos;

- a conservação da possibilidade de competir por investimentos mediante concessões regulatórias, com ou sem ancoragem em acordos internacionais.

Isso, porém, não afasta a possibilidade de conversão de uma rede latinoamericana - ou, em menor dimensão, da Aladi ou do Mercosul - de acordos em matéria de investimento. Essa rede poderia, num segundo momento, convergir para acordos regionais.

Há, porém, significativas dificuldades para a composição de um acordo regional amplo que tomasse um ponto de vista de países latino-americanos, entre os quais é possível mencionar:

- o bilateralismo dos TLCs americanos com países latino-americanos, bem como o Cafta, todos com capítulos específicos sobre investimentos, nos moldes dos modelos de TBI americanos;

- a falta de um consenso latino-americano sobre a necessidade de liberalizar o fluxo de capitais e de serviços;

- a postura brasileira contrária à adoção de Appri's;

- a complexidade da rede de cláusulas de nação mais favorecida pode limitar a adoção de soluções criativas voltadas às relações entre países em desenvolvimento, mas que não comportassem uma generalização unilateral ilimitada.

Esses limites podem significar que a entrada em redes bilaterais siga sendo uma alternativa de cooperação para a emissão de mensagens a respeito do consenso regional sobre a proteção de investimentos estrangeiros. No entanto, pelo menos a partir da análise dos padrôes atuais de distribuição dos acordos e de seu conteúdo, parece difícil imaginar a generalização em um acordo regional amplo ou, por outro lado, a inclusão de pautas de liberalização e de padróes mínimos nesta rede.

\section{Conclusões}

No Mercosul os Appri's não podem ser considerados como instrumentos relevantes de cooperação internacional para o estabelecimento de um bom clima de investimentos.

Em primeiro lugar, embora existam acordos envolvendo diversos países da Aladi, como a análise da rede argentina de acordos revela, esses não existem 
entre os países do Mercosul. À exceção de um acordo entre Paraguai e Uruguai, o fracasso dos Protocolos de Colônia e de Buenos Aires, alimentado pela ojeriza brasileira a estes acordos, faz com que as rede internacionais de Appri's e, particularmente, TBIs, não se estenda para dentro da sub-região. Por outro lado, entrementes, esses instrumentos não foram substituídos por nenhuma estratégia conjunta para o estabelecimento de um sistema sub-regional de promoção, proteção e regulação de investimentos. Isso, pelo menos em alguma medida, deve ser atribuído à percepção liberal do Tratado de Assunção, que põe bastante ênfase nos aspectos comerciais, deixando de lado as necessidades de políticas e estratégias regulatórias concertadas.

A análise do caso argentino indica, não obstante, uma modificação significativa a respeito do padrão de expansão das redes de Appri's, mostrando a presença cada vez mais constante de acordos entre países em desenvolvimento e, em particular, com os países da Aladi e da América Latina.

Embora seja necessária uma análise mais detalhada para sustentar a afirmação de que os acordos intra-regionais tendem a ser menos abrangentes, em termos de padrões mínimos e de liberalização, parece ser adequada a afirmação de que a extensão da rede para acordos entre países em desenvolvimento, embora não pareça ser essencial para o incremento do fluxo de investimentos, favorece a percepção política de que entre esses países há um consenso a respeito do estabelecimento de padrões de proteção de investimentos.

Nesse sentido, é importante compreender se a formação de redes de acordos entre países em desenvolvimento implicam a generalização de consensos a respeito da proteção e, portanto, possibilitariam a formação de costumes internacionais - o que parece ser bastante difícil quando se trata de acordos assimétricos ${ }^{23}$ ou se os modelos de acordos adotados poderiam ser um argumento a ser esgrimido contra padrões mais abrangentes de proteção. Para tanto, é necessária a análise da doutrina jurídica internacional, bem como das decisões proferidas por tribunais arbitrais em controvérsias entre investidores e Estados.

Tendo como base os dados levantados e analisados, no entanto, é possível afirmar que os padrões de acordos em matéria de investimento indicam a ausência de uma estratégia sub-regional concertada no âmbito do Mercosul para a utilização da juridificação internacional como um instrumento de regulação e harmonização em matéria de liberalização, padrões mínimos e, até mesmo, proteção internacional do investimento estrangeiro.

Recebido em 10 de agosto de 2006 Aprovado em 4 de outubro de 2006

\footnotetext{
${ }^{23}$ KISHOIYIAN, Bernard. "The utility of bilateral investment treaties in the formulation of customary international law". In: Northwester Journal of International Law and Business, n. 14, 1994.
} 


\section{Resumo}

A assinatura de tratados bilaterais de investimento por países em desenvolvimento é vista como uma estratégia para competir por capitais estrangeiros escassos. Este artigo discute possíveis padrões cooperativos na América do Sul partindo do conceito de bom clima de investimentos e considerando os acordos argentinos com outros paises em desenvolvimento.

\section{Abstract}

The signature of bilateral investment treaties by developing countries is regarded as a strategy to compete for scarce foreign capital. This article discusses the existence of possible cooperative patterns in South America starting from the concept of good investment climate and considering the Argentinean agreements with other developing countries.

Palavras-chave: Investimento estrangeiro, Tratados bilaterais, Cooperação regional. Key words: Foreign investment, Bilateral treaties, Regional cooperation. 